\title{
Comunicação e tecnologia no movimento estudantil mexicano \#YOSOY132
}

\author{
Communication and technology on the students' \\ movement \#YOSOY132
}

\begin{abstract}
Gabriel Bozza $^{[a]}$, Luciana Panke ${ }^{[b]}$
[a] Bacharel em Comunicação Social - Jornalismo pela Pontifícia Universidade Católica do Paraná (PUCPR), e mestrando em Comunicação na Universidade Federal do Paraná (UFPR), bolsista Reuni, Curitiba, PR - Brasil, e-mail: gabrielbozz@gmail.com

${ }^{[b]}$ Doutora em Ciências da Comunicação pela Universidade de São Paulo (USP), professora da Universidade Federal do Paraná (UFPR) nos cursos de graduação em Comunicação Social (Publicidade e Propaganda e Relações Públicas) e do Programa de Pós-Graduação em Comunicação, Curitiba, PR - Brasil, e-mail: lupanke@gmail.com
\end{abstract}

\section{Resumo}

Este trabalho discute o uso da comunicação tecnológica pelos jovens para sua visualidade, interação e transmissão de informação, principalmente quando integrantes de novos coletivos juvenis e movimentos sociais. O estudo apresenta o caso do movimento estudantil \#YoSoy132 que foi eficaz no uso das tecnologias da informação e comunicação na promoção de mudanças no andamento das eleições presidenciais mexicanas de 2012. O grupo de estudantes, amparado pelas TICs, conseguiu promover mudanças inéditas no panorama eleitoral mexicano. Além de engajar jovens, a ação atraiu diversos segmentos da sociedade, gerando ações online e nas ruas contra a eleição do presidente eleito, Enrique Peña Nieto e pela democratização dos meios de comunicação.e.

Palavras-chave: Comunicação política. Eleições presidenciais. Movimento estudantil. México.

\section{Abstract}

This paper discusses the use of technologic communication by young people for its visuality, interaction and transmission of information, especially members of new juvenile groups and social movements. The study presents the case of 
the students' movement \#YoSoy132 that was effective in the use of information and communication technology on promoting changes on the process of Mexican 2012 presidential elections. The group of students, sustained by the Technologies of Information and Communication, got to promote new changes on Mexican electoral view. Besides engaging young people, the action attracted many society segments, generating online and street actions against the election of the elected president, Enrique Peña Nieto, and for the democratization of the communication media.

Keywords: Political communication. Students' movement. Mexico. Presidential elections.

\section{Introdução}

As tecnologias da informação e da comunicação permitem novas formas de produção, transmissão e circulação de significados. Em ações coletivas e movimentos sociais facilitam a visualização e institucionalização das propostas, podendo gerar uma amplitude nem sempre planejada. Neste trabalho, trazemos reflexões sobre a colaboração das redes virtuais no fortalecimento das reivindicações de um grupo de estudantes mexicanos, durante as eleições presidenciais realizadas durante o primeiro semestre de 2012. O movimento intitulado \#YoSoy132 foi criado para se manifestar contra a candidatura do então candidato Enrique Peña Nieto e acabou ganhando proporção internacional, conforme veremos a seguir.

Para entender melhor a constituição do perfil do jovem na América Latina, Arce (2005) expõe as primeiras definições do que era ser um jovem latino-americano e que sofreram variações fundamentais ao longo dos séculos. Para ele, os "imaginários sociais dominantes" definiram a condição juvenil e "tradicionalmente, os depositários de ser jovem foram membros das classes altas, e somente no século XX se registraram alguns movimentos com reivindicações propriamente juvenis", que, por sua vez, determinavam opções diferenciadas dos adultos (ARCE, 2005, p. 117). No século XVI, era baseado em sistemas de pertencimento por estilos de vida e marcadores sociais.

No século XX, o jovem de classe média, como ator emergente, passou a caracterizar a condição juvenil. Na década de 1930, já havia uma visão excludente e seletiva dos jovens de colônias populares manifestantes, que não constituiam parte dominante da situação juvenil, e estabeleciam que em "colônias e bairros populares haviam delinquentes, vagos ou trabalhadores, mas não movimentos juvenis" (ARCE, 2005). Essa visão excludente prevalecia nos anos 50 e 60, quando surgiram os "rebeldes sem causa", que exigiam espaços na classe média, mas ainda assim os jovens de colônias populares latino-americanas eram vistos diferenciadamente dos de classe média e alta. Por sua vez, nas décadas de 1970 e 1980, os jovens das favelas, colônias e dos bairros populares configuram-se como novos atores juvenis com expressão. E, nas últimas décadas, movimentos feministas, culturais, étnicos e políticos vêm sendo observados com alta representatividade (ARCE, 2005, p. 118-122).

Segundo um levantamento da Comissão Econômica para a América Latina e Caribe (Cepal), realizado em $2011 \mathrm{com}$ dados coletados no mesmo ano, a população total de jovens entre 16 a 29 anos na América Latina era superior a $25 \%$, proporção semelhante ao maior índice já registrado entre meados de 1980 a 2000, quando essa população atingiu a marca de quase $30 \%$ da população total no contexto latino-americano.

Neste novo século, observa-se que a imersão nas tecnologias da comunicação propicia ao jovem a participação em distintos canais de comunicação na internet na busca de reconhecimento, legitimação e visibilidade dele e de agrupamentos ao qual pertence. Martín-Barbero (2006) diz que o desejo dos novos movimentos como dos jovens é de serem reconhecidos e fazerem-se visíveis na sociedade em sua diferença, e não tanto de serem representados. Para Albuquerque (1977), o movimento estudantil latino-americano possui um traço essencial que "reside no monopólio institucional da representação" e que em boa parte dos países latinos "o movimento estudantil obtém alguma forma de reconhecimento institucional, quando não é legalmente oficializado" (ALBUQUERQUE, 1977, p. 70). 
Martín-Barbero (2001) reconhece, entretanto, que há a existência de algumas utopias inerentes ao campo tecnológico e comunicacional. Para ele, a expansão das novas tecnologias a partir do fim dos anos 80 na América Latina fez surgiraideia de "democracia direta", enganosa para o autor, pois as redes informáticas não atribuem uma renovação da política, mas demonstram nesses discursos a existência da incapacidade da política representativa dos cidadãos (MARTÍN-BARBERO, 2001, p. 9-10). Todavia, Barbero diz que as tecnologias apontam outros modos de construir opinião pública e de dizer e fazer política, além disso, reforçam o direito à participação e capacidade dos indivíduos e das acomunidades de intervirem em decisões que afetem o seu viver.

A comunicação com auxílio de aparatos tecnológicos ocupa um lugar estratégico na configuração dos novos modelos de sociedade, conforme afirma Martín-Barbero (2006), e a visualidade eletrônicaé parte constitutiva da visualidade cultural, sendo um meio de um novo imaginário, principalmente para a juventude. Dessa forma, o computador representa uma "crescente cumplicidade entre a oralidade e a visualidade dos mais jovens" (MARTÍN-BARBERO, 2006, p. 74).

Por sua vez, Silverstone (2005) contraria a ideia anterior em alguns pontos e diz que as mudanças nas plataformas de veiculação informacional são uma forma de "nova retórica política". O autor pensa a tecnologia como política e, inclusive, que ela criaria um terceiro-excluído: o Estado-Nação.

As novas tecnologias da comunicação, por mais utópicas que sejam em alguns aspectos para Martín-Barbero, têm grande importância na modificação das relações humanas por sua "autonomia, domínio e velocidade", como aponta Wolton (2012), e principalmente pela "ideia de abertura, mas também a recusa das mídias de massa, o desejo de responder à inegável angústia antropológica, à tração pelo moderno, à procura de novas formas de solidariedade com os países mais pobres" (WOLTON, 2012, p. 83). O autor defende, ainda, que "não há comunicação sem vivência do tempo" e que o computador "acentua pela rapidez a ideia de uma possível diminuição das exigências do tempo" (WOLTON, 2012, p. 101).
O autor (2011) reconhece que "o sucesso da internet, especialmente, na juventude, é inegável" e que "três palavras resumem o charme da internet: velocidade-liberdade-interatividade" (WOLTON, 2011, p. 35-36). Para ele, existe a procura de uma outra comunicação, com os internautas buscando outras relações humanas e novas solidariedades (WOLTON, 2011, p. 38). Por sua vez, Downing (2002) corrobora defendendo a capacidade de oposição cidadã, aberta e velada, e destaca que a comunicação é uma necessidade vital para que os coletivos emovimentos sociais ocorram e prosperem, expandindo o âmbito das informações, reflexões e trocas.

A característica opositora dos coletivos sociais reforça que a apropriação tecnológica e o poder de visualização, pela dramatização e exposição em meios massivos, podem resultar em transformações socioculturais e político-eleitorais. Gómez (2006) vai ao encontro dessa definição ao apontarque estamos experimentando uma perspectiva tecnocêntrica no pensamento comunicacional, que demora para ser observada em virtude de o instrumental, sociocultural e, principalmente, o perceptivo estarem envolvidos e que levam ao surgimento de uma democracia cibernética, difundindo e produzindo conhecimentos que fortalecem cidadanias e principalmente o desenvolvimento das democracias.

Martín-Barbero (2005) aponta que as transformações tecnológicas não devem reduzir as mudanças socioculturais à sua dimensão tecnológica, como algo apenas técnico, ignorando o que foi produzido socialmente. A sua percepção é de que o avanço das redes digitais na América Latina é marcado por uma concepção altamente instrumental, não cultural e nem cidadã.

Pois o que a presença das TIC (tecnologias de informação e comunicação) está produzindo largamente e ao longo do mundo não é compreensível nem projetada politicamente, apenas a partir de uma visão integral capaz de permear em torno dos processos de desenvolvimento econômico-social e das práticas de participação democrática os impactos e as potencialidades dessas tecnologias ${ }^{1}$. (MARTÍN-BARBERO, 2005, p. 14, tradução nossa).

\footnotetext{
1 Pues lo que la presencia de las TIC (tecnologías de información y comunicación) está produciendo a lo largo y ancho del mundo no es comprensible ni proyectable políticamente más que a partir de una visión integral capaz de ubicar en el entorno de los procesos de desarrollo económico-social y
} 
Assim, para ele, o lugar da cultura na sociedade mudaria "quando a mediação tecnológica deixa de ser instrumental para espessar-se, densificar-se e converter-se em estrutural" (MARTÍN-BARBERO, 2005 , p. 24). A promoção de conectividade é o objetivo primordial para dotar a maioria da população latino-americana de acesso às tecnologias da informação e comunicação, e também de um projeto de "alfabetização virtual", conformada por um "conjunto de métodos mentais, hábitos operacionais e talento interativo" (MARTÍN-BARBERO, 2005, p. 31). Assim, a tecnologia não seria apenas um aparato tecnológico, mas também teria uma função de remeter "a novos modos de percepção e de linguagem, a novas sensibilidades e escritas" (MARTIN-BARBERO, 2005, p. 24).

\section{Comunicação eleitoral na Internet}

A chamada "comunicação política 2.0", uma possível forma de aproximação da juventude dos homens políticos, ainda é incipiente nos países latino-americanos. O presidente Barack Obama foi precursor nos Estados Unidos dessa nova forma de comunicação nas eleições de 2008 e inovou nos usos da tecnologia ao buscar a aproximação entre o cidadão e o político, abrindo a possibilidade de financiamento de sua campanha por instrumentos onlines, abrindo mão do financiamento público, e atraindo um público jovem pelo ativismo (FELTRIN; RAMINELLI, 2012, p. 291). Na América do Sul, a campanha da presidente da Argentina Cristina Kirchner foi a pioneira em 2007 ao implantar essa aproximação com os eleitores. Esses e outros poucos avanços registrados na história política online dos países latino-americanos, em que a maioria dos candidatos ainda utiliza a retórica como forma de persuasão na praça pública, condizem com o que Wolton (2004) chama de baixa capacidade dos políticos. A aproximação entre cidadãos e políticos seria a chance de obter um equilíbrio entre a política e a comunicação para revalorização da profissão dos políticos. A tecnologia pode ser um importante instrumento mobilizador e aglutinador desse público-alvo etário.

O surgimento de ações coletivas e movimentos sociais contemporâneos demonstram a insatisfação com os governantes e suas práticas políticas e monopólios. Lazzarini aponta que "en plena era de la comunicación, la clase política sufre de autismo discursivo y se niega a escuchar a los ciudadanos"2 (LAZZARINI, 2010, p. 151). $\mathrm{O}$ autor observa, ainda, que no "apogeo de Internet, candidatos y gobernantes pierden de vista que comunicar no es sólo hablar sino también, y fundamentalmente, escuchar"3 (LAZZARINI, 2010, p. 151).

Essa dificuldade de interação entre governantes e eleitores revela um novo perfil de eleitor na América Latina: um cidadão mais crítico, que busca participar das ações coordenadas. Em especial, a juventude encontra nas redes a possibilidade de falar e de ser ouvido de uma maneira que meios mais convencionais não permitiriam. Hill e Hugues (1998) apontam que "a Internet, é claro, tem o potencial de mudar esse fluxo de informação política e então revolucionar o processo de comunicação política" e pode impactar milhões de pessoas com a criação de páginas e softwares específicos.

Segundo Gutiérrez (2010), a comunicação política pode ser analisada pelos processos eleitorais, pois são um vínculo entre governo e governados por meio de inter-relações discursivas.

La comunicación política nace con las instituciones politicas, y su objeto parte de la necesidad de comunicar eficientemente todas las acciones que se asocian con el ejercicio de ellas. Generalmente se relaciona con la comunicación electoral, sobre la cual se interpreta todo aquello vinculado con la búsqueda del poder, ámbito que sin embargo desborda asociando política con comunicación. Las instituciones politicas, son, entonces, las mayores

\footnotetext{
de las prácticas de participación democráticas los impactos y la potencialidades de esas tecnologías (MARTÍN-BARBERO, 2005, p. 14).

2 Tradução livre: "em plena era da comunicação, a classe política sofre de autismo discursivo e se nega a escutar os cidadãos".

Tradução livre: "no auge da Internet, candidatos e governantes perdem de vista que comunicar não é só falar, mas também, fundamentalmente, escutar".
} 
productoras de información - de carácter político - de las sociedades contemporáneas. ${ }^{4}$ (GUTIÉRREZ, 2010, p. 146)

Os processos eleitorais passam a se alterar devido, justamente, às informações veiculadas pelas instituições políticas, as quais ganham repercussão na Internet provocando consequências não previstas por governos ou candidatos. Gutierrez alerta ao poder da informação e, se pensamos que estamos em uma sociedade cuja tendência é aumentar o desenvolvimento tecnológico na transmissão informativa, podemos inferir que há a necessidade de se repensar o papel dos agentes políticos nesse processo. Por exemplo, no momento em que se discute o desenvolvimento de "internet 3.0" da websemântica, ainda não vemos a comunicação política 2.0 atuar eficazmente como forma de estreitamento entre o eleitorado e políticos; isso porque a colaboração ainda não traduziu resultados e exige uma reciprocidade de objetivos e intenções do usuário-receptor. Os conceitos de internet 2.0 e 3.0 tiveram origem quando "emergiu como nova fase da tecnologia no qual o tema das comunidades virtuais, a produção e intercâmbio de informação por parte dos usuários e a construção de redes" ocuparam dentro da dinâmica digital um lugar de destaque (ROMERO, 2010, p. 291).

Pousada (2010) explica que a internet 2.0 se resume basicamente em "abertura, escuta e deixar o controle", e que elas podem trazer resultados positivos na incursão nesse cenário cibernético. A abertura seria o acesso à informação, como a transparência, disponibilidade e veracidade; e participação. A escuta é a abertura ao entendimento dos códigos de cada uma das consciências e não bombardear o cidadão-eleitor com conteúdos que possam caracterizar spam. E, por fim, deixar o controle é não submeter os outros aos seus gostos, pois é preciso aprender com cada um dos internautas (POUSADA, 2010, p. 233). A web 2.0, desde que bem empregada em campanhas e no dia a dia do governo de homens políticos, constitui um instrumento de aproximação com o público jovem.

En primer lugar, es innegable que las tecnologías 2.0 llegaron para quedarse y su uso en campañas irá in crescendo. La ampliación de la infraestructura tecnológica requerida (tanto a nivel de banda anch a como de telefonía celular, aún poco explotada), la instalación de las tecnologías 2.0 en la vida cotidiana de los ciudadanos (en su dimensión de individuos y consumidores), y los inmensos beneficios logísticos demostrados en la campaña (llegar a más cantidad de personas y a los jóvenes, convocar simpatizantes a actos o a trabajar como fiscales a un costo unitario muy bajo) son razones que confluyen para que los candidatos y las agrupaciones incorporen de manera más decidida estas herramientas. ${ }^{5}$ (POUSADA, 2010, p. 240, grifos nossos).

A falta de estratégias de comunicação digital na América Latina é reconhecida por muitos autores, que observam um desconhecimento dos políticos e seus assessores sobre como utilizá-las, em especial sobre as potencialidades de seu uso para interação e participação, e não apenas como um espaço promotor de informação de novidades de campanha ou de ações dos governantes. A Internet, desde que bem utilizada, tem o potencial que nenhum outro meio de comunicação possui de direcionamento da comunicação para cada público, como o público jovem em estudo, em formas distintas e dirigidas (FERNÁNDEZ-ARDÁIZ, 2010, p. 283).

$\mathrm{O}$ ativismo, uma das ideias-chave de participação nas campanhas online, é entendido como

\footnotetext{
${ }^{4}$ Tradução livre: "A comunicação política nasce com as instituições políticas e seu objeto parte da necessidade de comunicar eficientemente todas as ações que se associam a ela. Geralmente, se relaciona com a comunicação eleitoral, sobre a qual se interpreta tudo aquilo que está ligado á busca pelo poder, âmbito que, sem dúvida, associa a política com a comunicação. As instituições políticas são, então, as maiores produtoras de informação - de caráter político - das sociedades contemporâneas".

Tradução livre: "Em primeiro lugar, é inegável que as tecnologías 2.0 chegaram para ficar e seu uso em campanhas vai crescer. A ampliação da infraestrutura tecnológica (tanto em relação à banda larga como de telefonia), a instalação das tecnologias 2.0 no cotidiano dos cidadãos (em sua dimensão de indivíduos e consumidores), e os imensos benefícios logísticos demonstrados na campanha (chegar a mais pessoas e aos jovens, convocar simpatizantes para seus atos ou trabalhar como fiscais a um custo unitário muito pequeno) são razões que colaborar para que os candidatos e sua equipe incorporem de maneira mais decidida essas ferramentas".
} 
"práticas coletivas ou individuais de mobilização dos cidadãos eleitores em prol de uma candidatura", e pode ser como defesa ou publicização de reivindicações de "grupos ou causas de outra natureza no que tange a interesses, propósitos e demandas por resultados" (AGGIO, 2011, p. 186-187). Um caso eficaz de ativismo foi protagonizado pelo coletivo juvenil mexicano \#YoSoy132. Os jovens mobilizaram cidadãos e parcela expressiva da juventude mexicana e engajaram integrantes da sociedade civil contra a candidatura do presidenciável Enrique Peña Nieto, do Partido Revolucionário Institucional (PRI) nas eleições de 2012.

\section{O caso \#YoSoy132}

O movimento estudantil \#YoSoy132, na tradução livre \#EuSou132, teve início na Universidade Iberoamericana, uma instituição jesuíta e conservadora, e ganhou adesão de jovens de universidades públicas e privadas mexicanas. Com o tempo, conquistou também a adesão de jovens de várias universidades e sociedade civil em protestos nas ruas e nas redes sociais durante as eleições presidenciais do México, o que causou incerteza sobre o resultado das eleições de 1.o de julho, visto que os jovens de 16 até 29 anos de idade representaram quase $30 \%$ dos votantes. O movimento repercutiu internacionalmente, gerando, inclusive, videos de apoio de outros jovens mexicanos que vivem em diversos países (BOZZA, 2012).

No dia 11 de maio de 2012, o candidato Enrique Peña Nieto do Partido Revolucionário Institucional (PRI), líder nas pesquisas de opinião desde dezembro de 2011, foi surpreendido quase ao final da sua explanação na Universidade por um questionamento de estudantes da instituição. A tentativa de expor seu programa de governo aos estudantes do ensino superior durante o foro "Buen
Ciudadano Ibero" ${ }^{6}$ teve um desfecho inesperado e resultou em uma revolta estudantil.

Os jovens perguntaram ao presidenciável sobre o massacre policial ocorrido há seis anos na cidade de Atenco, Estado do México, quando o atual candidato era governador. A ação policial resultou na morte de dois jovens, um com 14 anos e o outro com 20 anos, 26 estupros de mulheres foram contabilizados pela Comissão Nacional de Direitos Humanos (CNDH) e 206 pessoas foram lesionadas e torturadas, sendo alguns casos de menores de idade. Ao todo foram violados dez direitos humanos a 209 pessoas $^{7}$. Os acusados não foram punidos. Ele afirmou em discurso que tomaria a mesma decisão pessoal para restabelecer a ordem e a paz se preciso.

Antes de concluir, aunque ya habia, lo habia hecho,
voy a responder a esta cuestionamiento sobre el tema de
Atenco, hecho que ustedes conocieron y que sin duda,
dejó muy claro, la firme determinación del gobierno,
de hacer respetar los derechos de la población del
estado de México, que cuando se vieron afectados, por
intereses particulares, tomé la decisión de emplear el
uso de la fuerza pública para res restablecer el orden
y la paz. y que en el tema, lamentablemente hubo
incidentes que fueron debidamente sancionados y que
los responsables de los hechos, fueron consignados ante
el poder judicial, pero reitero, reitero, fue una acción
determinadapersonalmente, que asumopersonalmente,
para restablecer elordeny lapaz, en el legitimo derecho
que tiene el estado mexicano, de hacer uso de la fuerza
pública, como además debo decirlo, fue validado por
la suprema corte de justicia de la nación. Muchas
gracias. ${ }^{8}$ (PEÑA NIETO, 2012).

Os estudantes vaiaram e protestaram contra o presidenciável, que enfrentou dificuldades para deixar o local. Encurralado num banheiro, ele precisou deixar o campus escoltado por seguranças ao grito

\footnotetext{
6 Na tradução livre: "Bom Cidadão Ibero".

Disponível em: < http://eleconomista.com.mx/columnas/columna-especial-politica/2012/05/21/pena-nieto-atenco>. Acesso em: 12 maio 2012.

8 Tradução livre: "Antes de concluir, ainda que já fizesse, o havia feito, vou responder a este questionamento sobre o tema de Atenco, fato que vocês conheceram e que sem dúvida, deixo muito claro, a firme determinação do governo, de fazer respeitar os direitos da população do estado do México, que quando se viram afetados, por interesses particulares, tomei a decisão de empregar o uso da força pública para restabelecer a ordem e a paz e que no tema, lamentavelmente houve incidentes que foram devidamente solucionados e que os responsáveis dos fatos foram consignados diante do poder judiciário, mas reitero, reitero,
} 
de "assassino", "fora daqui" e "feminicida". Antes de entrar num carro com vidros escuros, Peña Nieto acusou a universidade de ter sido manipulada por um grupo de provocadores e inimigos políticos infiltrados pagos por partidos adversários com o intuito de prejudicar seu discurso. Além disso, o candidato disse que aqueles jovens não eram universitários da instituição e um grupo com grande expressão. ${ }^{10}$

A repercussão das manifestações dos jovens tomou uma proporção enorme, a ponto de modificar o discurso eleitoral de Peña Nieto que passou a focar uma fala mais amena com vistas à conciliação com este público. No dia seguinte à manifestação, a equipe de EPN começou a veiculação de vídeos no Youtube com falas de jovens a seu favor e também divulgou a sua versão da palestra na Ibero. No dia 13, divulgou outro vídeo no seu canal oficial no Youtube, chamado "Oportunidades para os Jovens" no qual defendia ideias genéricas de geração de empregos, uma demanda social que, em especial, esta camada da população demandava.

No dia seguinte, "José Narro Robles, Reitor da Universidade Nacional Autônoma do México, e José Morales Orozco, reitor da Universidade Iberoamericana manifestaram seu apoio aos protestos de 11 de maio" (COUTIÑO, 2012, p. 46 apud BOZZA, 2012), enquanto os principais meios de comunicação do país acataram a ideia do presidenciável, divulgando seu discurso de conciliação. De acordo com o Portal Terra:
Estudiantes de la Ibero llaman 'cobarde' a Peña Nieto. El candidato agradeció a través de su cuenta de twitter, @EPN, a los estudiantes de la Universidad Iberoamericana por privilegiar y enriquecer a la democracia, esto, tras la serie de reclamos que recibió en su visita a dicha casa de estudios. ${ }^{11}$

Logo depois das manifestações, o jornal Universal repercutiu o fato:

EPN: escucharé siempre a jóvenes; respeto opiniones. A través de las redes sociales dijo que jamás rechazará la oportunidad de escuchar a la sociedad, mucho menos a los jóvenes, y que el diálogo y el debate son ejercicios que enriquecen a la democracia ${ }^{12}$.

Em resposta, 131 estudantes da universidade em uma ação coletiva gravaram um vídeo em que apresentam as carteiras universitárias com os seus números de matrículas, desmentindo as acusações. $\mathrm{O}$ vídeo de 11 minutos intitulado "131 Alumnos de la Ibero responden" "13 foi postado no YouTube em 14 de maio e obteve um efeito viral, gerando mais de 1 milhão de visualizações em poucos dias. O coletivo criou um site chamado Más de $131^{14}$ que utiliza o slogan "La verdad nos hará libres" ("A verdade nos fará livres") em que exigiu dos candidatos, instituições e meios de comunicação um processo democrático limpo e honesto durante as eleições.

Assim o \#YoSoy132 eclodiu, um site ${ }^{15}$ foi criado e as redes sociais ${ }^{16}$ auxiliaram na visualidade,

foi uma ação determinada pessoalmente, para restabelecer a ordem e a paz, e no legítimo direito que tem o estado mexicano, de fazer o uso da força pública, como devo dizer-lo, foi validado pela suprema corte de justiça da nação. Muito obrigado.” (PEÑA NIETO, 2012).

Disponível em: <http://operamundi.uol.com.br/conteudo/reportagens/22082/\%23yosoy132+levante+estudantil + motiva $+p$ rimavera + mexicana + antes + das + eleicoes $s h t m l>$. Acesso em:12 maio 2012.

${ }^{10}$ Disponível em: <http://brazilianpost.co.uk/11/06/2012/movimento-estudantil-ganha-forca-no-mexico/>. Acesso em: 12 maio 2012.

${ }^{11}$ Tradução livre: "Estudantes da Ibero chamam Peña Nieto de cobarde. O candidato agradeceu aos estudantes, através de sua conta no Twitter, por privilegiar e enriquecer a democracia, isso depois da série de reclamações que recebeu na sua visita àquela Universidade."

12 Tradução livre: "EPN: 'escutarei sempre os jovens, respeito opiniões'. Através das redes sociais disse que jamais rejeitará a oportunidade de escutar a sociedade, muito menos aos jovens e que o diálogo e o debate são exercícios que enriquecem a democracia."

${ }^{13}$ Vídeo "131 Alumnos de la Ibero responden” (Disponível em: <http://www.youtube.com/watch?v=P7XbocXsFkI>. Acesso em: 12 maio 2012).

${ }^{14}$ O coletivo da Universidade Iberoamericana utiliza o site www.somosmaisde131.com e mantém suas contas ativas no Facebook https:// www.facebook.com/mas131 e Twitter www.twitter.com/masde131

${ }^{15}$ O site oficial do movimento estudantil \#YoSoy132 é http://yosoy132.mx/

${ }^{16}$ O movimento estudantil utiliza a conta de Facebook https://www.facebook.com/yosoy132 e Twitter www.twitter.com/soy132 
e em poucos dias manifestações contrárias ao candidato priísta e aos meios de comunicação, principalmente as grandes cadeias de televisão Televisa e TV Azteca, se espalharam pelo país, mostrando que milhares de mexicanos seriam "o 132”. Apesar de contrário ao retorno de Enrique Peña Nieto e do partido criado na Revolução Mexicana (19101924), que governou o país por 71 anos, de 1929 a 2000, o movimento que utiliza o slogan "Por una Democracia autentica"17 se define como apartidário, mas respeita a pluralidade dos jovens cidadãos do movimento ${ }^{18}$.

Segundo levantamento do Cepal (2011), na América Latina, 49\% dos jovens entre 16 e 29 anos dizem não ter preferência partidiária e outros 51\% dizem possuir simpatia por algum(ns) partido(s). Quando se fala em apoio aos movimentos sociais, apenas 20\% dos jovens mexicanos disseram não estar dispostos a apoiá-los. Os indicadores favoráveis de predisposição à participação deles em ações coletivas demonstrou a vontade de pertencimento e participação social, carências não só do México, mas da juventude latino-americana. Um levantamento do Censo de População INEGI 2010 mostra que no México existem 29,7 milhões de jovens inseridos na faixa etária dos 15 a 29 anos.

O estudo do Cepal (2011) apresenta ainda grandes preocupações políticas, sociais e desigualdades latentes. Dados de 2009 mostram que cerca de $30 \%$ dos jovens mexicanos viviam na pobreza e $20 \%$ deles não trabalhavam e não estudavam, índice semelhante aos 30,3\% de jovens que viviam na pobreza na América Latina. Segundo o estudo, o México é o segundo pior país na América Latina quando avaliada a liberdade de participação política e de expressão entre os jovens. Apenas 15\% dos jovens mexicanos dizem que existe liberdade para participar da política, enquanto outros $20 \%$ de liberdade de expressão. Os números são aproximados da América Latina, 30\% e 28\%, respectivamente. Os indicadores de garantia de oportunidades para conseguir trabalho $(7 \%)$ e de que existe segurança social (11\%) também são bastante baixos, 19\% dizem pertencer à população discriminada do México, indicador próximo ao latino-americano.

Os jovens do movimento estudantil \#YoSoy132, pela primeira vez na história eleitoral do país, conseguiram promover um debate entre os candidatos à presidência, chamado \#Debate132. No México, os debates são organizados pelo Instituto Electoral Federal (IFE), órgão que organiza as eleições mexicanas, e são veiculados em cadeias nacionais de rádio e televisão que quiserem transmitir o evento.

O debate promovido pelos estudantes foi veiculado online e reuniu três dos quatro candidatos. Apenas Enrique Peña Nieto não compareceu ao evento por dizer não haver condições de imparcialidade. Os estudantes contaram com auxílio técnico do Google México, para que conseguissem transmitir o evento e conectar dez estudantes do país simultaneamente de suas residências para que fizessem perguntas aos candidatos no primeiro bloco. Os demais blocos foram de perguntas entre os candidatos e discussão sobre temas predeterminados em sorteio. O evento inédito transmitido pelo YouTube teve picos entre 90 e 97 mil visualizações. Ele foi transmitido ao vivo por vários veículos de comunicação, em sites e rádios, ampliando o poder de visualidade social.

A visibilidade almejada pelo \#YoSoy132 foi conquistada por ações desenvolvidas nas redes sociais, sites e canais alternativos de comunicação, como jornais impressos e online, informativos entregues em estações de metrô, aliados às encenações em protestos e marchas, e realizações de espetáculos musicais. O uso em massa da internet pelo coletivo mexicano vai ao encontro dos indicadores do Cepal (2011), inclusive, que mostram que cerca de $50 \%$ dos jovens mexicanos de 15 a 29 anos se conectavam diariamente à internet, 30\% utilizando café ou outro local pago, $28 \%$ em sua casa e $15 \%$ no local de estudo ou trabalho. A Pesquisa Nacional de Juventude (2010) aponta que 22,3\% dos jovens do sexo masculino entre 12 e 29 anos dizem usar redes sociais, contra $24,8 \%$ do sexo feminino, e o

\footnotetext{
${ }^{17} \mathrm{Na}$ tradução livre "Por uma Democracia autêntica".

${ }^{18}$ Disponível em: <http://www.redebrasilatual.com.br/temas/internacional/2012/06/movimento-mexicano-yo-soy-132-mobilizamilhares-no-mexico-mesmo-com-critica-a-seu-apartidarismo>. Acesso em: 18 nov. 2012.
} 
principal uso das redes sociais entre ambos sexos é para comunicação $(93,7 \%)$. O Facebook é apontado por $88,2 \%$ dos jovens como a rede de maior acesso.

O \#YoSoy132 utilizou-se de uma rede de movimentos sociais articulada e bem constituída pela internet em todos os estados mexicanos, chamadas de células, com integrantes em cada uma das localidades da nação. O movimento ampliou ainda sua visibilidade internacional e conta hoje com 52 representações locais nos cinco continentes, em cidades como Londres, Barcelona, Madri, Washington, Quebec, e com representantes em países como China e Austrália e nos latino-americanos Argentina, Chile e Colômbia.

A deficiente segurança pública e as constantes agressões e ameaças a integrantes do movimento levaram a Anistia Internacional a pedir proteção a todos os integrantes do movimento estudantil, que se assumiu como defensor dos direitos humanos (BOZZA, 2012). Fernanda Poulette, integrante do Comitê de Direitos Humanos do movimento \#YoSoy132, explicou o motivo do movimento se proclamar como defensor dos direitos humanos: por estarem alarmados e preocupados com as intensas agressões cometidas e ameaças que integrantes do movimento têm sofrido, assim decidiram se assumir como defensores dos direitos humanos. E ressaltou que estão defendendo os direitos fundamentais de liberdade de expressão. ${ }^{19}$

\section{Considerações finais}

No caso estudado, a utilização das ferramentas de comunicação revela formas de os jovens serem protagonistas sem ou com poucos métodos de filtragem e ganham adeptos em vários segmentos da sociedade. Com isso, conquistam visibilidade e se constituem em forças de protesto dentro de sistemas políticos.

As redes sociais de vídeo, por exemplo, possibilitam viralizar um conteúdo audiovisual, como conquistou o coletivo juvenil do \#YoSoy132 no México, em maio deste ano, pelo elo de solidariedade e necessidade de transformações na sociedade ansiadas por parcela significativa dos 29,7 milhões de jovens residentes no país. As redes de movimentos articuladas, auxiliadas pela internet, como a do grupo geracional juvenil \#YoSoy132, com células em todos os estados mexicanos e 52 representações internacionais demonstram laços não menos fortes entre essas conexões que se ampliaram durante as eleições mexicanas e ainda continuam atuantes e reivindicativas.

Para Wolton (2004), existe um laço forte entre comunicação e o modelo do Ocidente de modernização, mas o cidadão continua sendo um anão em ação em comparação ao gigante que é em informação. Ele percebe ainda um comportamento distanciado do cidadão do novo modelo político, incluindo o voto volátil, com a individualização do comportamento eleitoral, o fim das ideologias e capacidade para tomada de decisão que não a mesma de um grupo de pertencimento. A informação e a comunicação, assim, não podem substituir as estruturas sociais e as visões de mundo. A convocação do coletivo \#YoSoy132 à população para o voto útil nas eleições e da necessidade da participação principalmente dos jovens mexicanos nas urnas foi uma conquista alcançada, quando se percebe o distanciamento do eleitorado dos homens políticos e dos partidos políticos.

As redes alimentadas pelas tecnologias da informação, como a Internet, possibilitam que jovens de diferentes continentes compartilhem seus pensamentos, inquietações e insatisfações na esfera pública internacional, isto é, no globo conectado em rede. Apesar do acesso, uso e apropriação tecnológica serem distintas entre as populações latino-americanas, a grande adesão dos jovens as novas mídias nos últimos anos, canais eficazes de transmissão e circulação de informação em tempo real, possibilita a interação e troca de experiências e valores e compartilhamento de intenções entre eles. A baixa capacidade da comunicação política $2.0 \mathrm{em}$ impactar esse público geracional é visível e deve ser repensada. Escutar, incentivar a participação e o ativismo podem ser instrumentos práticos de aproximação entre o homem político e o cidadão-jovem-eleitor.

\footnotetext{
${ }^{19}$ Disponível em: <http://www.redpolitica.mx/nacion/ai-reconoce-yosoy132-como-defensor-de-dh>. Acesso em: 18 nov. 2012.
} 
A ausência de políticas públicas inclusivas de promoção e proteção social de jovens latino-americanos nos últimos anos pode ter levado ao surgimento do coletivo \#YoSoy132. No México existe uma Lei de Juventude criada em 1999, cujo Instituto Mexicano da Juventude, dependente da Secretaria de Educação Pública, é o responsável por coordenar e formular programas e planos de políticas públicas para a juventude, mas que ainda carece de dimensões que proporcionem formas de participação, sistema de pertencimento, oportunidades e capacidades dos jovens e inclusão tecnológica efetiva.

A internet cria um imaginário coletivo juvenil, em que cada jovem assume um papel e protagonismo na rede de computadores. A busca de reconhecimento potencializada pelo imediatismo e pela velocidade das TICs nas relações sociais auxilia na reconstrução da opinião pública, na busca de uma democracia participativa e no exercício da cidadania. Ela pode resultar ainda em transformações no modelo societal por meio de uma distinta forma de relacionamento que é apresentada, e não inclui o contato face a face. É claro que o aparato econômico, social, político e cultural deve sobressair sobre o tecnicista.

\section{Referências}

AGGIO, C. O. Internet, eleições e participação: questões-chave acerca da participação e do ativismo nos estudos em campanhas online. In: MAIA, R. C. M. et al. Internet e participação política no Brasil. Porto Alegre: Sulina, 2011. p. 175-190.

ALBUQUERQUE, J. A. G. Movimento estudantil e consciência social na América Latina. Rio de Janeiro: Paz e Terra, 1977.

ARCE, J. M. V. Juventudes latinoamericanas. In: MARTÍN-BARBERO, J. et al. América Latina, otras visiones desde la cultura: ciudadanías, juventud, convivencia, migraciones, pueblos originarios. Bogotá: Convenio Andrés Bello, 2005. Disponível em: <http:// books.google.com.br/books?id=N7LvIwYAv_EC\&pg $=$ PA13\&lpg $=$ PA13\&dq $=$ cultura $+y+$ nuevas + mediacio nes + tecnol $\% \mathrm{C} 3 \%$ B3 gicas\&source $=$ bl\&ots $=2$ nqKTK R0L0\&sig $=g 3$ MmzpBTRGPpvyXPPYw3YG9NSmM $\& \mathrm{hl}=\mathrm{pt}-\mathrm{BR} \& \mathrm{sa}=\mathrm{X} \& \mathrm{ei}=\mathrm{NlwEUNOIJ} 4 \mathrm{Oo} 8 \mathrm{QTDma} 2 \mathrm{u}$ $\mathrm{CA} \& v e d=0 \mathrm{CHwQ} 6 \mathrm{AEwCQ} \#_{\mathrm{v}}=$ onepage $\& \mathrm{q} \& \mathrm{f}=$ false $>$. Acesso em: 6 ju. 2012.
BOZZA, G. A. Movimento estudantil \#YoSoy132 e suas implicações nas eleições presidenciais mexicanas de 2012. Trabalho apresentado no XI Congresso Brasileiro de Marketing Político - POLITICOM. Curitiba: UFPR, 2012. Disponível em: $<$ http://politicom.com.br/wp-content/uploads/2012/02/ANAISPOLITICOM-20121.pdf>. Acesso em: 19 nov. 2012.

CEPAL-COMISSÃOECONÔMICA PARAAMÉRICA LATINA E O CARIBE. Informe Regional de Población em América Latina y el Caribe 2011 Invertir en juventud. Disponível em: $<$ http://www.cepal. org/publicaciones/xml/8/47318/Informejuventud2011. pdf>. Acesso em: 16 jul. 2012.

DOWNING, J.D. H. Mídia radical, rebeldia nas comunicações e movimentos sociais. São Paulo: Senac, 2002.

FELTRIN, L. P.; RAMINELLI, F. P. Política 2.0: uma nova política para novos eleitores. Revista Democracia Digital e Governo Eletrônico, n. 6, p. 286-310, 2012.

FERNÁNDEZ-ARDÁIZ, J. El Éxito de una Campaña Política 2.0. In: LARREA, J. J. et al. Comunicación Política en Latinoamérica: Gestión, Campañas y TIC’s. Ecuador: Editorial Comunicación Latinoamericana, 2010. p. $282-290$.

GÓMEZ, G. O. Comunicação social e mudança tecnológica: um cenário de múltiplos desordenamentos. In: MORAES, D. Sociedade midiatizada. Rio de Janeiro: Mauad, 2006.

GUTIÉRREZ, D. ¿Hacia un nuevo paradigma? La opinión pública y su impacto en la comulación política. In: IVOSKUS, D. et al. Cumbre mundial de comunicación política: cambios socioculturales del siglo XXI. Buenos Aires: Libros del Zorzal, 2010. p. 143-149.

HILL, K. A.; HUGUES, J. E. Cyberpolitics: citizen activism in the age of the Internet. Boston: Rowman \& Littlefield Publishers. Inc., 1998.

LAZZARINI, C. G. No es la tecnología, es la comunicación. In: IVOSKUS, D. et al. Cumbre mundial de comunicación política: cambios socioculturales del siglo XXI. Buenos Aires: Libros del Zorzal, 2010. p. 151-157. 
MARTÍN-BARBERO, J. Transformaciones comunicativas y tecnológicas de lo público. Metapolítica, México, v.5, n.17, p.46-55, 2001. Disponível em: <http://www. scribd.com/full/7405406?access_key=key-yv5814no1il4zduhxpe>. Acesso em: 16 jul. 2012.

MARTÍN-BARBERO, J. Cultura e Nuevas Mediaciones Tecnológicas. In: MARTÍN-BARBERO, J.et al. América Latina, otras visiones desde la cultura: ciudadanías, juventud, convivencia, migraciones, pueblos originarios. Bogotá: Convenio Andrés Bello, 2005. Disponível em: <http:/ /books.google.com.br/books?id=N7LvIwYAv_ $\mathrm{EC} \& \mathrm{pg}=\mathrm{PA} 13 \& \mathrm{lpg}=\mathrm{PA} 13 \& \mathrm{dq}=$ cultura $+\mathrm{y}+$ nuevas + me diaciones + tecnol $\% \mathrm{C} 3 \% \mathrm{~B} 3$ gicas $\&$ source $=$ bl\&ots $=2 \mathrm{nqK}$ TKR0L0\&sig=g3MmzpBTRGPpvyXPYw3YG9NSm $\mathrm{M} \& \mathrm{hl}=\mathrm{pt}-\mathrm{BR} \& \mathrm{sa}=\mathrm{X} \& \mathrm{ei}=\mathrm{NlwEUNOIJ} 4 \mathrm{Oo} 8 \mathrm{Q} T \mathrm{Tma} \mathrm{u}$ CA\&ved $=0 \mathrm{CHwQ} 6 \mathrm{AEwCQ} \# \mathrm{v}=$ onepage\&q\&f$=$ false $>$. Acesso em: 6 jul. 2012.

MARTÍN-BARBERO, J. Tecnicidades, identidades, alteridades: mudanças e opacidades da comunicação no novo século. In: MORAES, D. Sociedade midiatizada. Rio de Janeiro: Mauad, 2006. p. 71-86.

PEÑA NIETO, Enrique. Disponível em: Atenco enciende los ánimos contra Peña en la Ibero. 11 maio 2012. Disponível em: <http://www.elfinanciero.com. $\mathrm{mx} /$ index.php?option $=$ com_k2\&view $=$ item\&id $=1939$ 3\&Itemid=26> . Acesso em: 18 maio 2012.

POUSADA, V. D. Comunicación política 2.0 y participación. Percepciones de ciberactivistas y voluntarios. In: IVOSKUS, D. etal. Cumbre mundial de comunicación política: cambios socioculturales del siglo XXI. Buenos Aires: Libros del Zorzal, 2010. p. 231-243.

ROMERO, M. J. B. Política y Nuevas Tecnologías: ¿Origen de un Nuevo Ciudadano? In: LARREA, J. J. et al. Comunicación Política en Latinoamérica: Gestión, Campañas y TIC's. Ecuador: Editorial Comunicación Latinoamericana, 2010. p. 291-298.

SILVERSTONE, R. Por que estudar a mídia? São Paulo: Loyola, 2005.
WOLTON, D. Pensar a comunicação. Brasília: Ed. UnB, 2004.

WOLTON, D. Informar nãoé comunicar. Porto Alegre: Sulina, 2011.

WOLTON, D. Internet, e depois?: uma teoria crítica das novas mídias. 3.ed. Porto Alegre: Sulina, 2012.

Sites consultados:

<http:/ / brazilianpost.co.uk/11/06/2012/movimento-estudantil-ganha-forca-no-mexico/>. Acesso em: 12 maio 2012.

<http:/ / eleconomista.com.mx/columnas/columna-especial-politica/2012/05/21/pena-nieto-atenco $>$. Acesso em: 12 maio 2012.

$<$ http://operamundi.uol.com.br/conteudo/reportagens /22082/\%23yosoy $132+$ levante + estudantil + motiva + pri mavera + mexicana + antes + das + eleicoes.shtml $>$. Acesso em:12 maio 2012.

<http://www.redebrasilatual.com.br/temas/internacional/2012/06/movimento-mexicano-yo-soy-132-mobiliza-milhares-no-mexico-mesmo-com-critica-a-seu-apartidarismo>. Acesso em: 18 nov. 2012.

<http://www.redpolitica.mx/nacion/ai-reconoce-yosoy132-como-defensor-de-dh>. Acesso em: 18 nov. 2012.

<http:/ /www.youtube.com/watch?v =P7XbocXsFkI $>$. Acesso em: 12 maio 2012.
Recebido: 23/11/2012

Received: 11/23/2012

Aprovado: 30/11/2012

Approved: 11/30/2012 